\title{
Ana Mendieta: arte, cuerpo, género y naturaleza*
}

\author{
Filipe Ceppas, U. Federal de Río de Janeiro \\ filcepps@gmail.com
}

\begin{abstract}
Resumen
El texto analiza la obra de la artista cubana Ana Mendieta (1948-1985). En él, se establece un acercamiento a las investigaciones estéticas que, como la obra de Mendieta, buscan un diálogo con la tradición amerindia. El texto intenta mostrar la proximidad entre este diálogo propuesto por Mendieta y perspectivas filosóficas como las de Gilles Deleuze y Jacques Derrida, como clave para interpretar la particularidad de su obra. Mostramos que la dificultad de localizar o aprehender esta obra se relaciona con la dificultad que nosotros, occidentales, tenemos para acercarnos a las culturas amerindias, más allá del reconocimiento teórico de su importancia.
\end{abstract}

Palabras clave

Ana Mendieta, cultura amerindia, performance, liminaridad, naturaleza.

\section{Ana Mendieta: art, body, gender and nature}

\begin{abstract}
This text analyzes the work of Cuban artist Ana Mendieta (1948-1985). It provides a theoretical approach to aesthetic studies that search for a dialogue with the Amerindian tradition, as does Mendieta's work. The text tries to show the proximity between this proposed dialogue and the philosophical perspectives of Deleuze and Derrida, as a key to understanding the particularity of her work. We show that the difficulty of locating or grasping Mendieta's work relates to the difficulty that all Western citizens have in approaching Amerindian cultures beyond the theoretical recognition of its importance.
\end{abstract}

Keywords

Ana Mendieta, Amerindian culture, performance, liminarity, nature.

* Recibido: 14 de marzo de 2016 / Aceptado: 9 de mayo de 2016. 
Hace treinta años (en septiembre de 1985) murió Ana Mendieta, artista poco conocida fuera de los circuitos artísticos especializados. En este texto, nos proponemos presentar y analizar algunas características de su trabajo, como un homenaje tardío. Nos centramos en el diálogo que su trabajo nos permite establecer con las culturas indígenas, primordiales, amerindias, pues éste es un aspecto poco explorado por la crítica.

La violencia, en el trabajo de Ana Mendieta, suele identificarse en las obras en que la artista explora la sangre, el estupro y elementos de la santería. Hay muchos textos acerca de la artista, sobre todo escritos feministas, que resaltan la presencia de este elemento en relación con cuestiones de género, pertenencia y raza de una artista, mujer, exiliada y latinoamericana frente a un mercado de arte predominantemente masculino y euroanglocéntrico (Blocker, 1999; Hudson, 2011; Özbay et al., 2007). Pero, vistas en su conjunto, las obras de Mendieta trazan un eje que desplaza el sentido de esos enfrentamientos políticos y artísticos a una dimensión quizás más difícil y compleja: la centralidad de elementos indígenas y precolombinos para hablar de (aunque ya vamos a cuestionar este "hablar de") los orígenes, la muerte, el sexo, la relación del cuerpo con la naturaleza y, a través de ella, una indiscernibilidad o integración entre el yo y el todo, la vida, el universo.

La violencia que, en el trabajo de Mendieta, se conecta con una cierta apropiación de la cultura precolombina, o la violencia que esa apropiación actualiza, la (im)posibilidad de una armonización y domesticación, o incluso de apropiación de las fuerzas que se suelen identificar a la naturaleza: éste es un horizonte que nos invita a repensar el arte, sus potencias, a través de los medios específicos con los cuales la artista elabora y registra sus performances. La obra de Mendieta moviliza las antinomias que marcan nuestro entendimiento de las relaciones entre el arte y la dicotomía naturaleza-cultura y, por tanto, nos invita a investigar la pretensión de apropiación o incorporación de los referenciales amerindios para hablar de los orígenes, la muerte, la mujer, etc. Quizás el mejor concepto para hablar de esa experiencia sea el trazo, que Derrida ha explorado en diversas ocasiones en conjunción con el "entre", una liminaridad siempre marcada por lo femenino y por la violencia de toda y cualquier inscripción (Derrida, 1972).

Pero el arte a partir de la modernidad no quiere solamente "hablar de": no es representacional, sino que, más bien, como subraya Rancière, trabaja las (o en las) rupturas entre la intención del autor, los medios de la obra, sus materiales, sus formas, su contenido semántico y su recepción. Y eso es lo que posibilita lo propiamente político del régimen estético:

No se va de una visión del espectáculo a una comprensión del mundo y de una comprensión intelectual a una decisión de acción. Se va de un mundo sensible a otro 
mundo sensible que define otras tolerancias e intolerancias, otras capacidades e incapacidades. Lo que es operante son las disociaciones: la ruptura de una relación entre el sentido y el sentido, entre un mundo visible, un mundo de afección, un régimen de interpretación y un espacio de posibilidades; es la ruptura de las marcas sensibles que permitían estar en su sitio en un orden de las cosas. (Rancière, 2008: 7475).

Los movimientos artísticos a los cuales la obra de Mendieta es afín, el body art y el land art, profundizan además el proceso de desublimación del arte. Entre otras cosas, esto quiere decir que el arte deja de ser el sitio en el cual el hombre podría encontrar el sentimiento de vértigo en cuanto a su posible unidad con la naturaleza y con su destino. En este sentido, la unidad con la naturaleza incesantemente retrabajada por Mendieta adquiere un estatuto problemático, de lo cual la artista fue perfectamente consciente. La búsqueda del origen es conjugada con la percepción de que no hay pasado a redimir y efectuada sobre todo a través de la reapropiación de las culturas amerindias y arcaicas. Pero la noción de "reapropiación" es, también ella, problemática. Sería más correcto decir re-creación, re-invención o re-actualización, para usar una expresión de la propia artista.

En la trayectoria de la artista, sus siluetas van progresiva y consistentemente convirtiéndose en la imagen antropomórfica central de una diosa de la fertilidad de tiempos remotos. Esta imagen y la elección de los sitios donde sus performances fueron realizados y registrados hacen del arte de Mendieta un acontecimiento único en la historia del arte occidental; o, podríamos decir: eso hace que su obra sea, quizás, la que ha llegado más cerca de un contacto con lo que se suele llamar "arte primitivo". Pero, ¿qué especie de "contacto" es ese? ¿Cuál es el sentido o la fuerza de esa re-actualización para nosotros?

Entre las interpretaciones de la obra de Mendieta, predominan las que resaltan sus dimensiones políticas y existenciales, que son, sin duda, ineludibles. Pero el consenso, ya marcado por análisis y valoraciones divergentes u opuestas, termina acá. Más allá de los temas del feminismo, el exilio y la reactualización de referenciales de las artes neolíticas y amerindias, en el límite de las convicciones personales de la artista acerca de su potencia mágica, civilizatoria, existencial, acerquémonos a la dificultad de encontrar nuestra propia mirada, nuestro "punto de fuga" a través de la crítica. Quizás sea una cierta indecidibilidad acerca del sentido de su obra lo que la hace tan rica y desafiante. Las "fuerzas tectónicas", arquetípicas, que emanan de su obra vienen de su carácter de liminaridad, de superficie y abertura. Pero no solamente en el sentido modernista de la "obra abierta" (habría que tener en cuenta el rechazo de la artista a ubicar su trabajo bajo las órbitas del modernismo, aunque sus conexiones iniciales con los trabajos de artistas como Marcel Duchamp, Frida Kahlo y otros sean cruciales). El carácter 
de liminaridad y abertura de su obra adviene del referencial mismo al que recurre y es en eso que reside su violencia.

La dificultad que tenemos para acercarnos a las culturas primordiales (término preferible a "primitivas", con su carga de inferioridad y su resonancia evolucionista) es un tema clásico de la antropología. Mendieta se pregunta, de una manera por demás sencilla e incluso, se podría decir, ingenua, por qué las cosmovisiones primordiales se encuentran olvidadas. En su crítica a Claude LéviSrauss, Derrida ha subrayado el riesgo de afirmar a los indígenas como "el otro" en su pureza, como si allá estuviera lo más propio del hombre: el riesgo, en una palabra, del esencialismo (Derrida, 1967). Mendieta también ha sido criticada por su supuesto esencialismo con relación a una imagen idealizada de lo femenino, identificado con su conexión primordial a la naturaleza en las culturas antiguas, que solamente dicho esencialismo sería capaz de lograr (Ruido, 2002). Pero, más allá de una retórica rousseauniana presente de hecho en algunos de los textos de Claude Lévi-Strauss, podría decirse que éste estuvo suficientemente vacunado contra cualquier idealización ingenua de las culturas indígenas. Lo mismo se puede decir de Mendieta. Es necesario ir más allá, o más acá, de la retórica de las convicciones personales y sus vacilaciones.

Analizando sus influencias iniciales y más importantes, la académica y crítica de arte Jane Blocker llama la atención sobre la lectura que Mendieta hizo de Mircea Eliade:

Sus ideas [de Mendieta] acerca del mundo "primitivo" repiten las de Eliade al punto de que las performances de esos rituales abrasadores adquieren eficacia como una repetición de los rituales que afirman el origen que el libro de Eliade [...] describe aunque Mendieta incluso por poco no ha incinerado ese libro. [...] el libro de Eliade es un artefacto problemático en la performance de Mendieta. Ello ubica esas culturas ["primitivas"] en un spectrum de desarrollo en lo cual no hay ningún "retorno posible" a la vida primitiva, que Eliade salvaguarda con seguridad en un pasado corrosivo (Blocker, 1999: 39).

A la reflexión de Mendieta acerca de la cuestión del origen la acompaña por tanto un gesto sintomático: simultáneamente, de aceptación y rechazo. Es lo que Blocker, siguiendo a Peggy Phelan, denomina "marca a través de la desaparición". La obra de Mendieta está llena de elementos que lo confirman. Por ejemplo, a medida que la obra avanza, el cuerpo de la artista también desaparece, pero su "marca", en especial en sus siluetas, se hace cada vez más fuerte. Aquí sería fundamental referirnos a las diversas técnicas de marcas, inscripciones, apariciones y desapariciones en las culturas indígenas. Nosotros, occidentales, solamente las conocemos a través de las investigaciones arqueológicas y etnográficas. La sumersión artística, en cambio, opera en otra lógica, conforme a las teorías antropológicas como la de Lévi-Strauss: por ejemplo, a medio camino 
entre el conocimiento y el mito. De nuevo encontramos aquí la idea de la liminaridad.

La figura del hechicero es central. El chamán es el único capaz de establecer un contacto significativo (que aplaca los ánimos, que cura, etc.) con lo no-humano. Pero las distinciones de los indígenas entre lo humano y lo no-humano no corresponden a nuestras distinciones comunes de cultura, naturaleza y sobrenaturaleza. Desde el punto de vista del perspectivismo amerindio, la naturaleza primordial es humana, cultural (Castro, 2002). Lo no-humano son seres (algunos animales y espíritus) que se distancian de esa naturaleza común y es tarea del chamán la invocación y la comunicación con esos seres. El arte de los indígenas también revela esa "anterioridad" de lo cultural. Un hombre que no se pinta o no se adorna, no es hombre. Se podría creer que los motivos del arte corporal o de los objetos fabricados son retirados del mundo físico y, por eso, son más bien la proyección de la naturaleza sobre la organización social. Pero esos motivos ya están comprendidos por los indígenas a partir de su organización social: el jaguar, el urubu, el maíz, etc., participan igualmente de las mismas relaciones y divisiones vigentes en las relaciones sociales y en las representaciones mitológicas.

Así, una primera cuestión que nos interesa, cuando pensamos en la potencia de un arte que busca re-actualizar un contacto más primordial con la naturaleza a través de la re-actualización del imaginario de los indígenas o de las civilizaciones antiguas, es que, en realidad, no es posible presuponer unas fuerzas míticas que existirían en una dimensión arquetípica sin la historia y sin la intervención del hombre. Lo que el arte puede "invocar" es la posibilidad de una actualización de esos modos alternativos de vivir y concebir las relaciones entre lo humano y lo no-humano que implican otros modos de vivir y concebir el cuerpo, la muerte, el tiempo, la concepción, etc.

Una segunda cuestión está referida a la dimensión ritualística necesaria a esa "invocación". Hay que comprender los mecanismos de registro de Mendieta como estrategias de desespectacularización. A medio camino entre el performance y la instalación, sus series son grabadas en películas y fotografías. Sus registros son como registros etnográficos de rituales, de sus elementos y sus vestigios. La ausencia de sonido intensifica aún más esa atmosfera etnográfica. Sus imágenes nos presentan ídolos que nos desafían a algo más que a la simple tentativa de interpretación y comprensión. Al contrario del mito, en el que se establecen relaciones de especies naturales que representan metafóricamente las relaciones sociales, el rito establece una relación de contigüidad metonímica, en la que se utilizan las categorías sociales para indicar las relaciones interespecíficas (Castro, 2002: 466). El rito crea una virtualidad dinámica, donde 
los polos (mujer, fluidos, fuerza, muerte, etc.) entran como en un momento de indiscernibilidad (464).

El performance, el land art y el body art, en sus diversas formas, intentan acercarnos a una vivencia ritualística del arte. Ana Mendieta también lo intenta, pero a eso agrega una actitud antimodernista (o posestructuralista) importante. No hay quizás mejores teorías para comprender su gesto que las filosofías de Gilles Deleuze y Jacques Derrida, aunque por caminos que son muy distintos. Las definiciones mismas de la potencia del arte en Deleuze (1980) bordean las intersecciones del arte con la hechicería y el animismo, en que se conjugan lo femenino (el devenir-mujer) y lo no-humano. En Derrida (1972), lo femenino también surge como dimensión central para pensar el arte, desde el punto de vista de su naturaleza liminar (el himen, el entre, la borda), con su carácter de violencia e indecidibilidad.

La virtualidad dinámica, el "contacto significativo" que el chamán produce, activa relaciones entre las cosas y sus órdenes (tipos de animales, tipos de espíritus, de vivientes y de muertos, etc.). Así también lo hace el trabajo de Mendieta, que nos lanza directamente a una región fronteriza o borrosa donde no sabemos qué hacer con estos elementos naturales fundamentales, con todas estas intensidades. Si nosotros, occidentales, nos encontramos tan distantes de ese tipo de "lógica de lo concreto", ¿lo máximo que podríamos hacer sería una remisión -sea lúdica, a través del arte, sea racional, a través de la antropologíaa esos modos distintos de vivir y concebir la vida, la muerte, las cosas? Y la potencia de esa remisión, ¿`se agotaría en una función de crítica a nuestro modo de vida? ¿Esa es toda su potencia, su fuerza, su "violencia"? En esta dificultad, en la pregunta sobre la posibilidad de re-actualizar las potencias, las concepciones y las vivencias en juego en los mitos y ritos de las culturas amerindias y arcaicas, se encuentra la fuerza de un arte que, como el de Mendieta, no se deja capturar, ni por el mainstream, ni por lo exotizante.

\section{Referencias}

Blocker, Jane (1999). Where is Ana Mendieta? Identity, performativity, and Exile. Durham: Duke.

Castro, Eduardo Viveiros de (2002). A Inconstância da alma selvagem. São Paulo: Cosacnaif.

Deleuze, Gilles; Guatarri, Félix (1980). Capitalisme et schizophrénie, tome 2. Mille plateaux. Paris: Minuit.

Derrida, Jacques (1972). La dissémination. Paris: Seuil.

Derrida, Jacques (1967). De la grammatologie. Paris: Minuit. 
Hudson, Michelle (2011). Beyond Self: Strategic Essentialism in Ana Mendieta's "La Maja de Yerba". Art and Design Theses. Paper 72. Georgia: GSU. Recuperado el 17 de octobre de 2011 de http://digitalarchive.gsu.edu/art_design_theses/72.

Özbay, Müge; Eviner, Ínci; Akgün, Tevfik (2007). Deterritorialization, Performative Identity and Uncanny Representation of Woman's Body in the Works of Ana Mendieta. XVII International Congress of Aesthetics. Ankara [manuscrito].

Rancière, Jacques (2008). Le spectateur émancipé. París: La Fabrique.

Ruido, María (2002). Ana Mendieta. Hondarribia: Nerea.

Viso, Olga (2008). Unseen Mendieta. Munich: Prestel. 